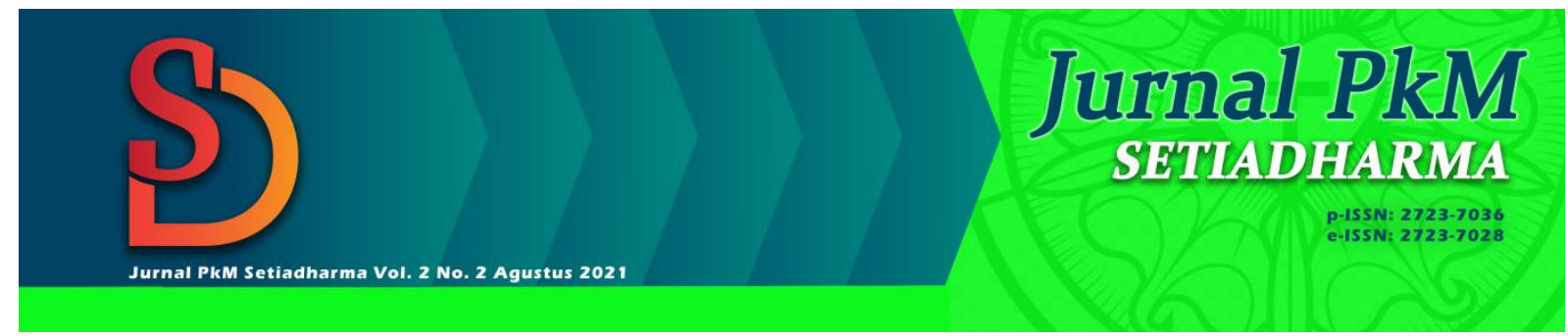

\title{
PEMBINAAN KEROHANIAN KRISTEN DI LAPAS ANAK DAN WANITA KELAS II TANGERANG
}

\author{
Roce Marsaulina, Rajiman Andrianus Sirait \\ Sekolah Tinggi Teologi Moriah Tangerang \\ rocemarsaulina1@gmail.com, rajimanandrianussirait@gmail.com
}

\section{Diterima:}

25-06-2021

Direview:

01-07-2021

23-07-2021

Direvisi:

10-07-2021

27-07-2021

Diterbitkan:

30-07-2021

Keywords:

christian spirituality, construction, correctional institution

Kata Kunci: kerohanian Kristen, lembaga pemasyarakatan, pembinaan

\section{Abstract}

Correctional Institution is a place to carry out the construction of inmates. For those who go to prison can cause stress to their lives. The implementation of construction is one of its functions so that the target citizens can live their lives as creatures of God and good members of society. The implementation of coaching activities specifically in the spiritual field can increase one's spiritual values, even can awaken their spirit as well. The implementation method conducted in management of the jailbird using the method of lectures or preaching online through the Zoom application and also come directly to them as a form of concern and also as a solution to break the chain of pandemic Covid 19. This guidance activity, according to the participants is very close. Their enthusiasm to return to worship shows that there is a growing spirit, from that spirit to a sign that their spirituality is getting better organized. Guidance is one of the various tasks of man in nurturing and shaping the ideal human being. The behavior of the inmate, which is a criminal act is a violation of the law that needs attention.

\section{Abstrak}

Lembaga Pemasyarakatan (LP) merupakan tempat untuk melaksanakan pembinaan narapidana. Bagi mereka yang masuk ke dalam penjara dapat mengalami stres. Pelaksanaan pembinaan yang dilakukan merupakan salah satu fungsinya agar warga binaannya dapat menjalankan hidupnya sebagai makhluk Tuhan dan anggota masyarakat yang baik. Pelaksanaan kegiatan pembinaan secara khusus di bidang rohani dapat meningkatkan nilai-nilai rohani seseorang, bahkan dapat membangkitkan semangat mereka juga. Metode pelaksanaan yang dilakukan di Lapas Anak dan Wanita kelas 2 Tangerang menggunakan metode ceramah atau khotbah secara daring melalui aplikasi Zoom dan juga mendatangi langsung sebagai bentuk kepedulian dan juga sebagai solusi untuk memutus mata rantai pandemik Covid-19. Kegiatan bimbingan ini, menurut para peserta sangat memberkati. Antusias dari mereka untuk kembali beribadah menunjukkan bahwa adanya semangat yang terus tumbuh, dari semangat tersebut menjadi penanda bahwa spiritualitas mereka semakin tertata dengan baik. Bimbingan adalah salah satu dari berbagai tugas manusia dalam membina dan membentuk manusia yang ideal. Tingkah laku dari narapidana, yang merupakan tindakan kriminal merupakan pelanggaran hukum yang perlu mendapatkan perhatian. 


\section{PENDAHULUAN}

Lembaga Pemasyarakatan atau sering disebut menurut UU No. 12 Tahun 1995 tentang Pemasyarakatan Pasal 1 ayat 3, Lembaga Pemasyarakatan (LP) merupakan tempat untuk melaksanakan pembinaan narapidana dan anak didik pemasyarakatan. ${ }^{1}$ Bagi mereka yang dimasukkan ke dalam sebuah Lembaga Pemasyarakatan mereka akan diberikan pembinaan yang berdasarkan Pancasila. Menurut Mitha Thoha pembinaan adalah suatu tindakan yang melalui sebuah proses untuk dapat menghasilkan atau menyatakan yang lebih baik. Dengan demikian proses tersebut menunjukkan adanya suatu kemajuan, peningkatan dan pertumbuhan evaluasi dalam berbagai kemungkinan untuk berkembang atau adanya peningkatan. Hal ini menjadikan pembinaan sangat diperlukan sehingga Lembaga Pemasyarakatan lebih dapat memperhatikan resosialisasi narapidana. ${ }^{2}$

Pelaksaanan pembinaan yang dilakukan merupakan salah satu fungsinya agar warga binaannya dapat menjalankan hidupnya sebagai makhluk Tuhan dan anggota masyarakat yang baik. Dalam Pasal 1 butir 2 Undang-Undang Pemasyarakatan, menentukan bahwa sistem Pemasyarakatan adalah: "Suatu tatanan mengenai arah dan batas serta cara pembinaan warga binaan pemasyarakatan berdasarkan pancasila yang dilaksanakan secara terpadu antara pembina, yang dibina, dan masyarakat untuk meningkatkan kualitas warga binaan pemasyarakatan agar menyadari kesalahan, memperbaiki diri, dan tidak mengulangi tindak pidana sehingga dapat diterima kembali oleh lingkungan masyarakat, dapat aktif berperan dalam pembangunan, dan dapat hidup secara wajar sebagai warga yang baik dan bertanggung jawab."3 Pada Pasal 6 pada UU Pemasyarakatan, menyebutkan bahwa, "Pembinaan WBP oleh Lembaga Pemasyarakatan serta Pembimbingan WBP oleh BAPAS (Balai Pemasyarakatan). Pembinaan tersebut khusus kepada Narapidana dewasa dan anak-anak yang dibagi menjadi 2 (dua) jenis pembinaan, yaitu pembinaan kepribadian seperti program kerohanian sesuai agama yang dianut WBP dan pembinaan kemandirian seperti program untuk melatih skill guna bekal kembali ke masyarakat. "4

Bila melihat hasil penelitian T.H. Holmes dan Rahe yang dikutip oleh Fauziah dengan menggunakan inventori the Social Readjustment Rating Scale (SRRS) menunjukan bahwa peristiwa kehidupan yang dapat menimbulkan stres adalah salah satunya masuk penjara dengan berada pada peringkat ke empat dengan nilai sebesar enam puluh tiga. Warga binaan bisa stres karena kurangnya penerimaan diri terhadap kondisinya untuk mendekam di penjara, sehingga mereka mudah tersinggung dan marah jika keinginannya tidak terwujud, ada orang yang membuatnya kesal, ketidakbebasan ruang dan waktu untuk menjalani hari-harinya. ${ }^{5}$ Bambang Purnomo berpendapat bahwa pembinaan berserta pembimbingan dapat dibuat menjadi program antara lain bimbingan: 1. Aspek mental, melalui kegiatan keagamaan agar menumbuhkan rasa bersalah sehinga mereka tidak mau mengulangi kejahatannya lagi, 2. Aspek sosial, dengan memberikan arahan agar mereka dapat hidup berbaur dengan masyarakat kelak, 3. Aspek keterampilan, dibuatkan kegiatan yang sesuai dengan bakat

\footnotetext{
1 Muhyar Nugraha, "Pola Pembinaan Narapidana Di Lapas Paledang Bogor Sebagai Pelaksanaan Sistem Pemasyarakatan," Jurnal Yustisi 4, no. 2 (2017): 16.

2 M Kevin Yosiva Arza and Padmono Wibowo, "NUSANTARA : Jurnal Ilmu Pengetahuan Sosial" 8, no. 1 (2021): 207-220.

${ }^{3}$ Undang-Undang Nomor 12 Tahun 1995 Tentang Pemasayarakatan., n.d.

4 Candra Dian Tawawi and Padmono Wibowo, "Analisis Bentuk Pembinaan Narapidana Di Lembaga Pemasyarakatan Kelas IIA Kalianda,” Wajah Hukum 4, no. 2 (2020): 255.

${ }^{5}$ F. Fauziah, "Pengaruh Pembinaan Kerohanian Terhadap Kemampuan Anger Management Warga Binaan," Doctoral dissertation, UIN Sunan Gunung Djati Bandung 6, no. April (2018): 140.
} 
PEMBINAAN KEROHANIAN KRISTEN DI LAPAS ANAK dan ... (Roce Marsaulina \&

Rajiman Andrianus Sirait)

dan minat para warga binaan, 4. Pembimbingan untuk tetap menjaga keamanan, 5. Pembimbingan lainnya seperti penyuluhan kesehatan ataupun yang berhubungan dengan masyarakat kelak. ${ }^{6}$

Melihat hal di atas maka kegiatan pembinaan secara khusus di bidang rohani seperti adanya ibadah persekutuan di dalam Lapas, dan edukasi akan pentingnya untuk menanggalkan cara-cara hidup lama (yang menjadi penyebab 'masuknya' ke LAPAS) perlu dilakukan.7 Dalam meningkatkan nilai-nilai spiritual seseorang terdapat beberapa aspek yang meliputi: 1. Hubungan dengan sesuatu yang tidak diketahui di dalam kehidupan. 2. Menemukan arti dan tujuan hidup sehingga mampu menggunakan sumber dan kekuatan dalam diri sendiri. 3. Mempunyai keterikatan diri sendiri dengan yang maha tinggi. ${ }^{8}$ Selain itu sjpiritual juga merupakan kecerdasan yang ada dalam diri seseorang sehingga mampu membantu menemukan dan mengembangkan bakat bawaan, otoritas batin, kemampuan membedakan yang benar dan salah serta kebijaksanaan. ${ }^{9}$

Muajiz mengatakan dalam jurnal yang dikutip oleh Maisah bahwa kecerdasan spiritual dapat mengangkat fungsi jiwa sebagai perangkat, sehingga ia memiliki kemampuan dan kepekaan dalam melihat makna yang ada di balik kenyataan apa adanya. ${ }^{10}$ Mengacu kepada yang di atas dapat dilihat bahwa tujuan PkM ini agar setiap warga binaan tersebut semakin memiliki sikap hidup atau perbuatan yang baik dan juga mereka dapat menyadari bahwa kehidupan mereka juga bermakna tidak hanya untuk mereka tetapi bagi orang lain juga (Mat. 5:16). Selain itu proses ibadah dalam doa dan pujian yang dilakukan dalam PKM ini juga memiliki tujuan agar adanya dampak sukacita (Mzm. 126:1-2), pemulihan (Neh. 7:1, 66), menambah dan memperkuat iman (Rm. 10:17), agar semakin bertumbuh juga dalam kekudusan (Mzm. 22:3).11

\section{METODE PELAKSANAAN}

Pelaksanaan Kegiatan Pengabdian Masyarakat menggunakan konsep bimbingan rohani dimana peserta diberikan pembekalan rohani yang berdasarkan Alkitab yang disampaikan dengan metode ceramah atau khotbah. Dari bimbingan rohani diharapkan peserta dapat mampu menyembuhkan kekecewaan dari kesalahan yang sudah dilakukan, semakin dekat dengan Tuhan dan juga untuk menumbuhkan semangat di dalam dirinya.

Adapun langkah kegiatan pengabdian masyarakat yang akan dilaksanakan:

a. Penulis yang telah rutin diundang untuk melayani di LAPAS Anak dan Wanita Kelas II Tangerang, yang beralamat di Jl. Daan Mogot Km-23 No.28C,

\footnotetext{
${ }^{6}$ Ruslan Renggong, Memahami Perlindungan HAM Dalam Proses Penahanan Di Indonesia (Jakarta: Prenamedia Group Jakarta, 2014).

${ }^{7}$ Hasahatan Hutahaean et al., "Penyuluhan Terhadap Warga Binaan Pemasyarakatan LAPAS Kelas IIA Binjai ; Sikap Mengampuni," MATAPPA : Jurnal Pengabdian Kepada Masyarakat 4 (2021): 246.

${ }^{8}$ Simon M Tampubolon, "Mengembangkan Kecerdasan Spiritual Mahasiswa Di Perguruan Tinggi," Humaniora 4, no. 2 (2013): 1205.

9 Monty P. Satiadama and Fidelis E. Waruwu, Mendidik Kecerdasan Pedoman Bagi Orang Tua Dan Guru Dalam Mendidik Anak Cerdas (Jakarta: Pustaka Populer Obor, 2003), 42.

10 Maisah, "SPIRITUAL QUOTIENT MELALUI PELATIHAN BERBASIS NILAI SPIRITUAL GURU MTs Maisah," Cakrawala Pendidikan no 2 (2016): 219.

11 Rajiman Andrianus Sirait, "Tujuan Dan Fungsi Musik Dalam Ibadah Gereja Dibagi Menjadi Dua Bagian :," Tonika : Jurnal Penelitian dan Pengkajian Seni 4, no. 1 (n.d.): 19.
} 
RT.005/RW.013, Tanah Tinggi, Kec. Tangerang, Kota Tangerang, Banten, berkoordinasi untuk melaksanakan kegiatan pelaksanaan bimbingan rohani;

b. untuk menentukan kesepakatan mengenai konsep dan rencana pelaksanaan bimbingan rohani;

c. pelaksanaan Bimbingan Rohani dilakukan selama 2 (dua) bulan dari bulan Mei-Juni 2021 dengan total pertemuan sebanyak 4 kali, melaui aplikasi Zoom dan juga datang di LAPAS Anak Dan Wanita Kelas II Tangerang, untuk memberikan masker.

\section{HASIL DAN PEMBAHASAN}

Lembaga Pemasyarakatan bukanlah akhir dari segala kehidupan, dan bukan tempat akhir bagi para warga binaan yang berada di Lapas. Bimbingan adalah salah satu dari berbagai tugas manusia dalam membina dan membentuk manusia yang ideal. Oleh karena itu, tingkah laku narapidana yang merupakan tindakan kriminal merupakan pelanggaran hukum yang perlu mendapatkan perhatian.

Istilah bimbingan merupakan dari istilah bahasa Inggris guidance. Dalam kamus bahasa Inggris guidance dikaitkan dengan kata asal guide, yang diartikan sebagai berikut; menunjukkan jalan (showing the way), memimpin (leading); menuntun (conducting); memberikan petunjuk (giving instruction); mengatur (regulating); mengarahkan (governing); memberikan nasehat (giving advice). ${ }^{12}$ Berdasarkan hal tersebut maka bimbingan adalah memberikan pengetahuan dengan menunjukkan jalan, memimpin, menuntun dan memberikan nasehat kepada seseorang dengan menggunakan metode psikologis dan sebagainya. Dalam memberikan pembinaan penulis menyadari Alkitab adalah dasar yang harus digunakan, seperti yang ditegaskan oleh Ruth Behick dalam A Biblical Psychology of Learning yang dikutip oleh Tung, bahwa Alkitab adalah sumber pengetahuan manusia dan memberikan dasar-dasar pembelajaran. ${ }^{13}$ Alkitab memiliki kebenaran dan keandalan untuk membangun iman kepada Kristus. ${ }^{14}$ Dengan adanya kegiatan bimbingan dan penanaman nilai-nilai positif melalui pembinaan keagamaan, penulis mengharapkan para warga binaan dapat mengimplementasikan nilai-nilai tersebut dalam kehidupan mereka sehari-hari, sehingga mereka tidak lagi mengulangi kesalahan yang sama di masa-masa yang akan datang.

Penulis memandang bahwa pada dasarnya pola sistem pemasyarakatan yang dianut dalam Undang-Undang Nomor 12 tahun 1995 tentang pemasyarakatan telah banyak mengadopsi Standard Minimum Rules for the Treatment of Prisoners (SMR) yang dilihat dari tujuan akhir pemasyarakatan, di mana pembinaan dan pembimbingan terhadap narapidana. Ketika penulis melangsungkan kegiatan PkM ini, penulis melihat respons yang sangat baik dari pihak pengelola Lapas dan memang tujuan dari UndangUndang itu benar-benar diterapkan.

Bila kita tinjau dari Mazmur 19:13, "Siapakah yang dapat mengetahui kesesatan? Bebaskanlah aku dari apa yang tidak kusadari." Dan juga Roma 12:2, "Janganlah kamu menjadi serupa dengan dunia ini, tetapi berubahlah oleh pembaharuan budimu, sehingga kamu dapat membedakan manakah kehendak Allah: apa yang baik, yang berkenan kepada Allah dan yang sempurna." Kedua nas Alkitab ini menggambarkan bahwa

12 WS Winkel, Bimbingan Dan Konseling Di Institusi Pendidikan (Jakarta: Gramedia, 1997), 65.

${ }^{13}$ Khoe Yao Tung, Filsafat Pendidikan Kristen (Yogyakarta: Penerbit ANDI, 2013), 322.

14 Aprianus Ledrik Moimau, "Kehandalan Alkitab Menjadi Fondasi Bagi Pengajaran Tentang Yesus Kristus" 3, no. 1 (2020). 
PEMBINAAN KEROHANIAN KRISTEN DI LAPAS ANAK dan ... (Roce Marsaulina \&

Rajiman Andrianus Sirait)

ketidaksadaran manusia merupakan suatu beban jiwa manusia, dan kesadaran akan ketidakmampuan berbuat sesuai dengan nilai-nilai spiritual agama di hadapan Allah. Oleh karena itu peran dari pembinaan terkhususnya mereka warga binaan yang beragama Kristen perlu dilakukan. Hal tersebut untuk membangun, memberitakan dan berteologi dalam Kerajaan Allah. Karena jika tidak ada yang mau membimbing mereka maka dapat dibayangkan begitu banyak pribadi yang akan tersesat.

Adapun kegiatan PkM di Lapas Anak dan Wanita Kelas II Tangerang dilakukan secara bertahap. Tahapannya adalah sebagai berikut:

1. Pembagian masker pada tanggal 17 Mei 2021, sebagai kegiatan pertama, dan juga sebagai respons akan kepedulian di masa pandemi Covid 19 maka dilakukan proses pembagian masker. Pada saat ini juga penulis mengatur waktu untuk pertemuan selanjutnya.

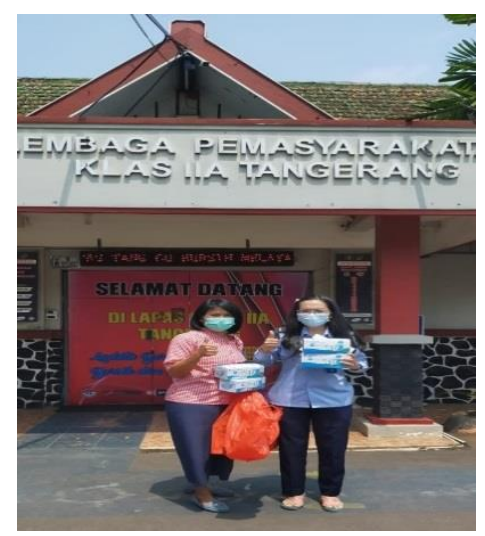

Gambar 1: Kegiatan Pembagian Masker Secara Simbolis

2. Bimbingan Rohani pada tanggal, 3 Juni 2021, melalui aplikasi Zoom, hal ini dilakukan karena kondisi keadaan dunia yang sedang mengalami wabah pandemi Covid 19 masih terus berlangsung. Hal ini membuat akses untuk tatap muka secara langsung di tempat tidak bisa dilakukan. Dalam pertemuan ini dilakukan proses ibadah seperti biasa dengan memuji menyembah Tuhan dan mengajak para warga binaan di Lapas untuk samasama berdoa. Firman Tuhan disampaikan oleh Roce Masraulina, M.Pd dari Filipi 4:4 dengan tema "Bersukacitalah senantiasa dalam Tuhan." Dalam isi khotbahnya dikatakan sukacita adalah ciri dari orang percaya yang merupakan kualitas orang percaya sejak pertama kali ia mengalami perjumpaan dengan Kristus. Sukacita merupakan karunia dari Tuhan yang bersifat dinamis yang dapat diganggu oleh dosa oleh, karena itu untuk kita tetap dapat bersukacita kita tetap harus menjaga hubungan kita dengan Tuhan Yesus Kristus. Sukacita juga bisa menjadi salah satu tanda dari kemajuan iman seseorang. 


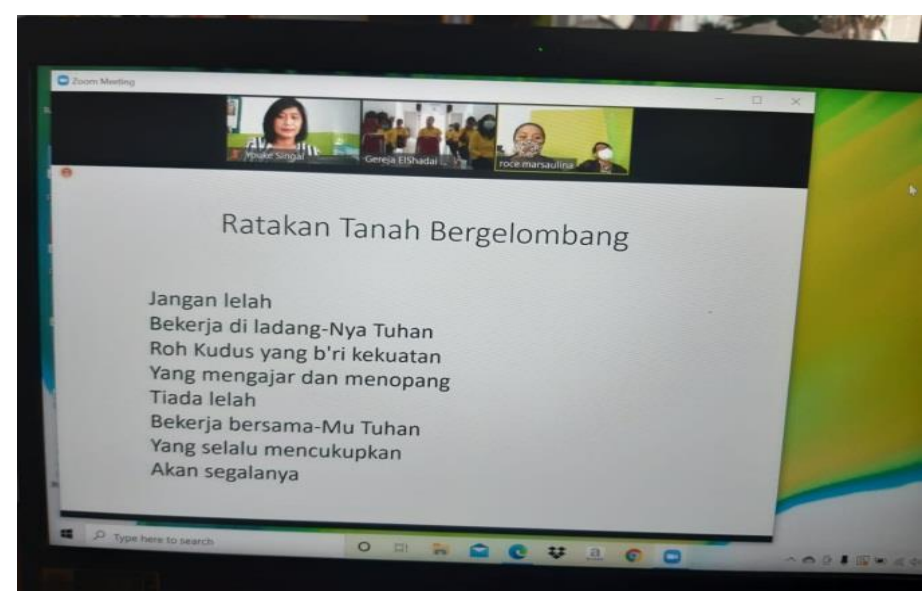

Gambar 2: Kegiatan Kedua

3. Bimbingan Rohani Hari Kamis, 14 Juni 2021, melalui aplikasi Zoom. Firman Tuhan disampaikan oleh Roce Masraulina, M.Pd dari Kisah Para Rasul 15:35Kisah 16:3. Dengan tema: "Bangkit Dari Sebuah Kegagalan". Tujuan dari sharing firman Tuhan ini agar mereka dapat bangkit dan tetap kuat menghadapi kehidupan. Hal yang penting ditekankan pada isi sharing tersebut adalah bukanlah soal "apakah kita semua pernah jatuh?", melainkan apakah kita bangkit dari kejatuhan yang kita alami. Pada kesempatan ini juga para warga binaan ikut peran aktif dalam melayani, mereka mengambil bagian untuk berdoa, dan mereka aktif juga mencatat akan firman yang disampaikan. Bahkan antusias mereka terus terlihat dibandingkan pada pertemuan sebelumnya.

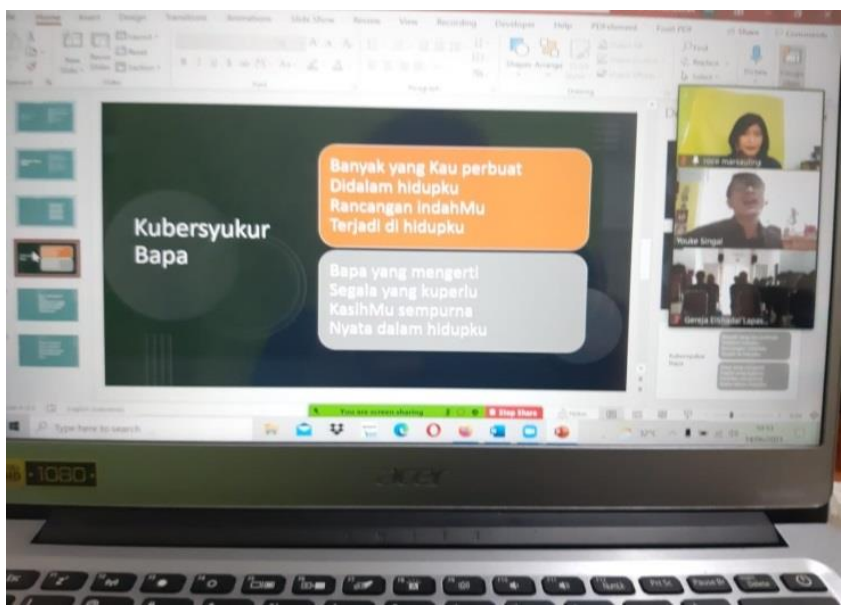

Gambar 3: Kegiatan Keempat

4. Pembagian masker pada tanggal 22 Juni 2021, sebagai kelanjutan acara ketiga, dan juga sebagai respons akan kepedulian di masa pandemi Covid 19 maka dilakukan proses pembagian masker. 


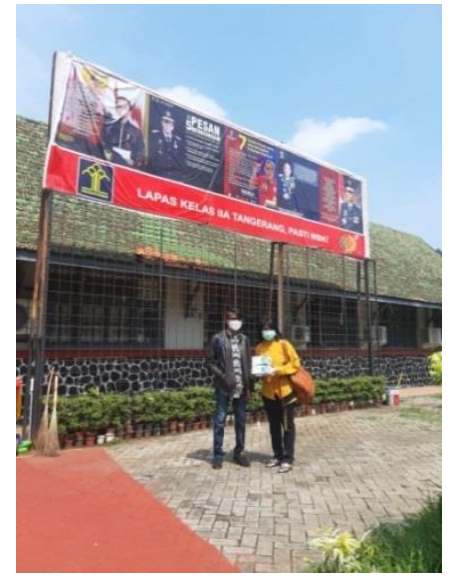

Gambar 4: Kegiatan penyerahan masker

Pada kegiatan terakhir ini, mereka memberikan respons yang sangat baik, di mana mereka menanyakan kapan kembali membuat ibadah lagi. Mereka mengatakan sangat terberkati, antusias mereka untuk kembali beribadah menunjukkan bahwa adanya semangat yang terus tumbuh, dari semangat tersebut menjadi penanda bahwa spiritualitas mereka semakin tertata dengan baik.

\section{KESIMPULAN}

Kegiatan pengabdian masyarakat berupa kegiatan bimbingan rohani Agama Kristen ini dilaksanakan sebanyak 4 kali, melalui aplikasi Zoom. Selain itu, penulis dan tim juga datang ke LAPAS Anak dan Wanita Kelas II Tangerang untuk membagikan bantuan berupa masker sebagai bentuk kepedulian kepada mereka terlebih lagi disaat pandemi Covid 19. Kegiatan Bimbingan Rohani di Lapas Anak dan Wanita Kelas II Tangerang dilakukan dengan metode ceramah berupa khotbah yang berdasarkan ayat Alkitab dan puji-pujian lagu rohani. Bimbingan adalah salah satu dari berbagai tugas manusia dalam membina dan membentuk manusia yang ideal. Ketidaksadaran manusia merupakan suatu beban jiwa manusia, dan kesadaran akan ketidakmampuan berbuat sesuai dengan nilai-nilai spiritual agama di hadapan Allah. Oleh karena itu peran dari pembinaan terkhususnya mereka warga binaan yang beragama Kristen perlu dilakukan. Dari kegiataan tersebut, mereka dapat dibangkitkan semangatnya, serta spiritual mereka tetap terpelihara dengan baik. 


\section{DAFTAR PUSTAKA}

Arza, M Kevin Yosiva, and Padmono Wibowo. "NUSANTARA : Jurnal Ilmu Pengetahuan Sosial" 8, no. 1 (2021): 207-220.

Fauziah, F. "Pengaruh Pembinaan Kerohanian Terhadap Kemampuan Anger Management Warga Binaan." Doctoral dissertation, UIN Sunan Gunung Djati Bandung 6, no. April (2018): 139-164.

Hutahaean, Hasahatan, Saut Togi, Marihot Panjaitan, Bonar Simarmata, and Luis Jimmy. "Penyuluhan Terhadap Warga Binaan Pemasyarakatan LAPAS Kelas IIA Binjai; Sikap Mengampuni." MATAPPA : Jurnal Pengabdian Kepada Masyarakat 4 (2021): 244-250.

Maisah. "SPIRITUAL QUOTIENT MELALUI PELATIHAN BERBASIS NILAI SPIRITUAL GURU MTs Maisah." Cakrawala Pendidikan no 2 (2016): 217-224.

Moimau, Aprianus Ledrik. "Kehandalan Alkitab Menjadi Fondasi Bagi Pengajaran Tentang Yesus Kristus" 3, no. 1 (2020).

Nugraha, Muhyar. "Pola Pembinaan Narapidana Di Lapas Paledang Bogor Sebagai Pelaksanaan Sistem Pemasyarakatan." Jurnal Yustisi 4, no. 2 (2017): 15-27.

Renggong, Ruslan. Memahami Perlindungan HAM Dalam Proses Penahanan Di Indonesia. Jakarta: Prenamedia Group Jakarta, 2014.

Satiadama, Monty P., and Fidelis E. Waruwu. Mendidik Kecerdasan Pedoman Bagi Orang Tua Dan Guru Dalam Mendidik Anak Cerdas. Jakarta: Pustaka Populer Obor, 2003.

Sirait, Rajiman Andrianus. "Tujuan Dan Fungsi Musik Dalam Ibadah Gereja Dibagi Menjadi Dua Bagian :" Tonika: Jurnal Penelitian dan Pengkajian Seni 4, no. 1 (n.d.): 11-21.

Tampubolon, Simon M. "Mengembangkan Kecerdasan Spiritual Mahasiswa Di Perguruan Tinggi." Humaniora 4, no. 2 (2013): 1203-1211.

Tawawi, Candra Dian, and Padmono Wibowo. "Analisis Bentuk Pembinaan Narapidana Di Lembaga Pemasyarakatan Kelas IIA Kalianda.” Wajah Hukum 4, no. 2 (2020): 254.

Tung, Khoe Yao. Filsafat Pendidikan Kristen. Yogyakarta: Penerbit ANDI, 2013.

Winkel, WS. Bimbingan Dan Konseling Di Institusi Pendidikan. Jakarta: Gramedia, 1997. Undang-Undang Nomor 12 Tahun 1995 Tentang Pemasayarakatan., n.d. 